Intususcepción ileo-cólica en paciente adulto, secundaria a lipoma

Natalia Apentchenko Eriutina

Fabiola Lucena Navarro

Ágata Laguno de Luna

Cirugía general y digestivo, $H$. Costa de Sol (Marbella)

\title{
IMAGEN MÉDICA
}

Mujer de 58 años, sin antecedentes y una colonoscopia normal 3 años antes, intervenida de apendicitis, que acudió a urgencias por dolor en epigastrio de 6 horas de evolución sin otros síntomas. Presentaba buen estado general. El abdomen era doloroso en fosa ilíaca derecha con defensa a ese nivel, sin masas y ruidos abdominales normales. No presentaba alteraciones analíticas. Se realizó radiografía de abdomen (Imagen 1) y TC abdominal con contraste intravenoso (Imágenes 2 y 3). 


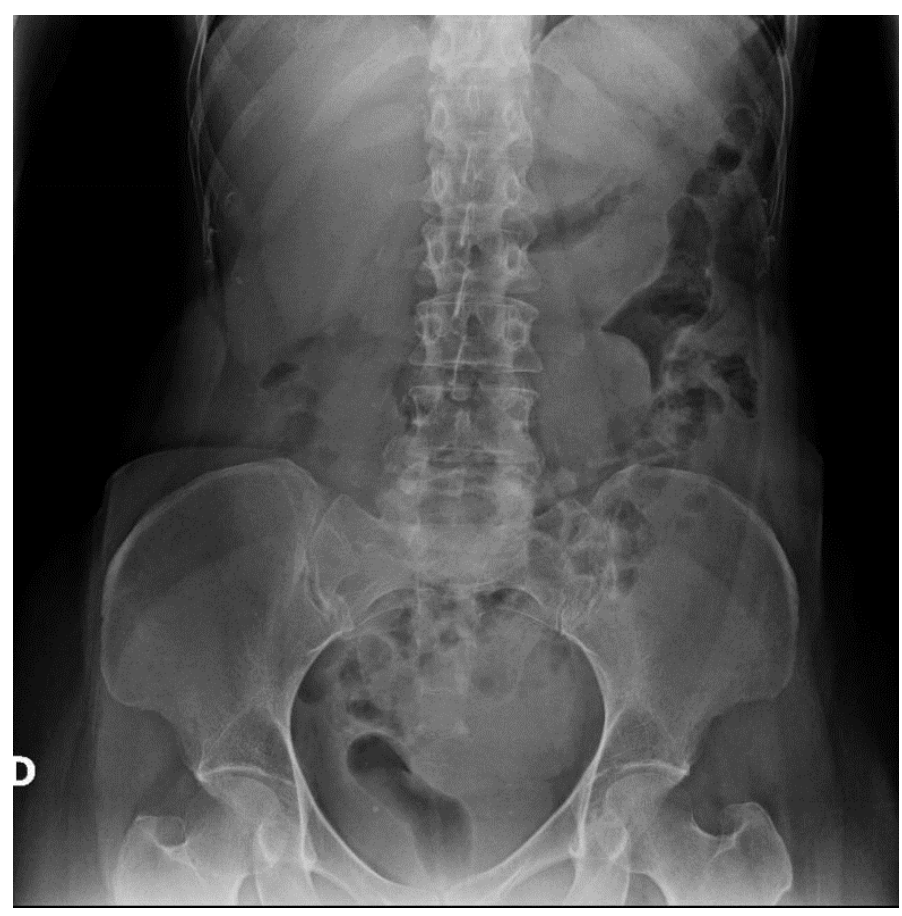

Imagen 1: Radiografía simple de abdomen. En el flanco izquierdo se aprecia imagen redondeada radioopaca, correspondiente a la cabeza de la invaginación.

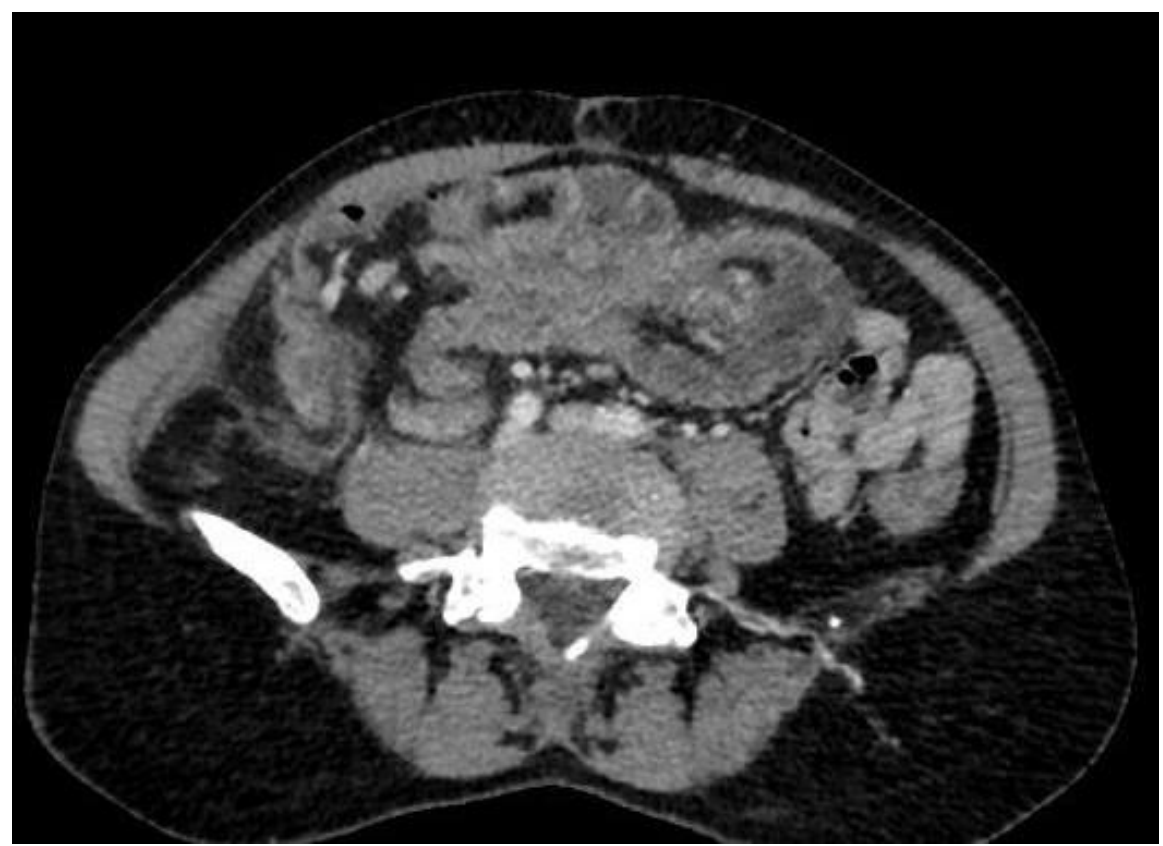

Imagen 2: Corte axial que muestra la clásica imagen de ojo de buey (lesión de densidad grasa a nivel de válvula ileocecal y la invaginación intestinal que la rodea). 


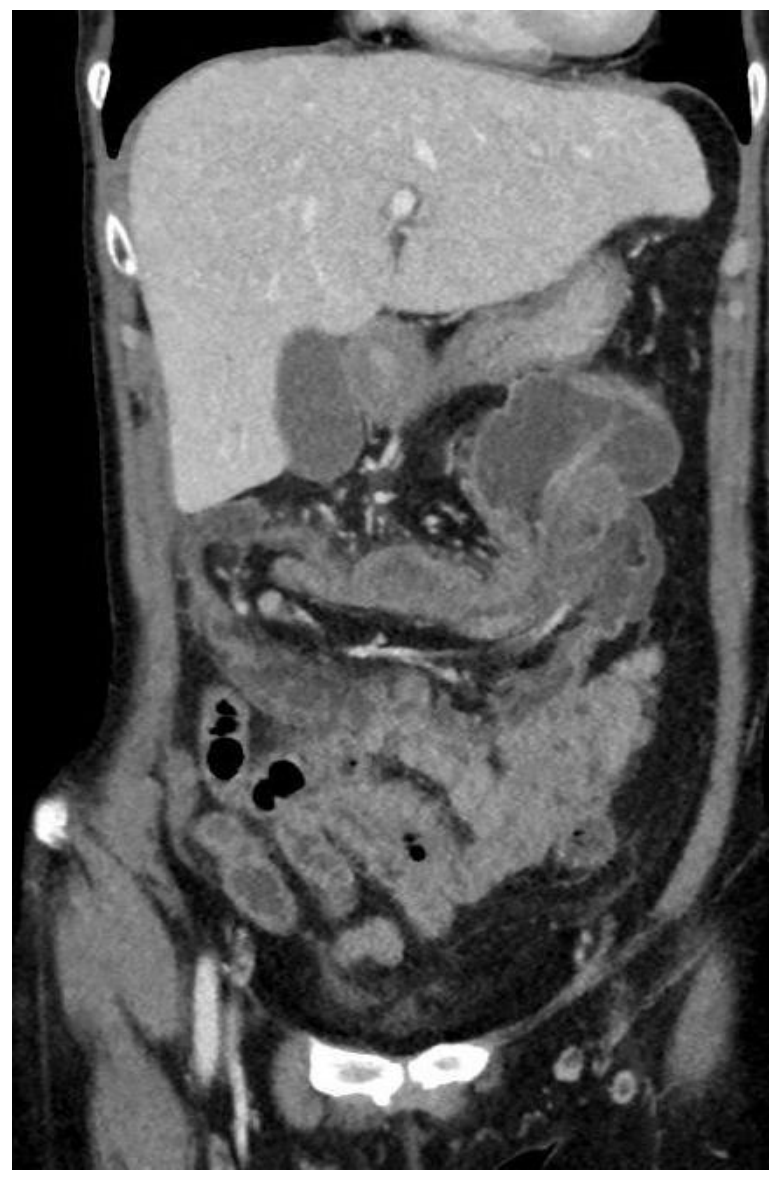

Imagen 3: Corte coronal. Invaginación del íleon y colon hasta ángulo esplénico y el eje vascular del mesenterio invaginado.

Se realizó laparotomía urgente, confirmándose existencia de una invaginación intestinal (Imágenes 4 y 5), completando desinvaginación y resección ileocecal. La anatomía patológica confirmó el diagnóstico de lipoma submucoso. 


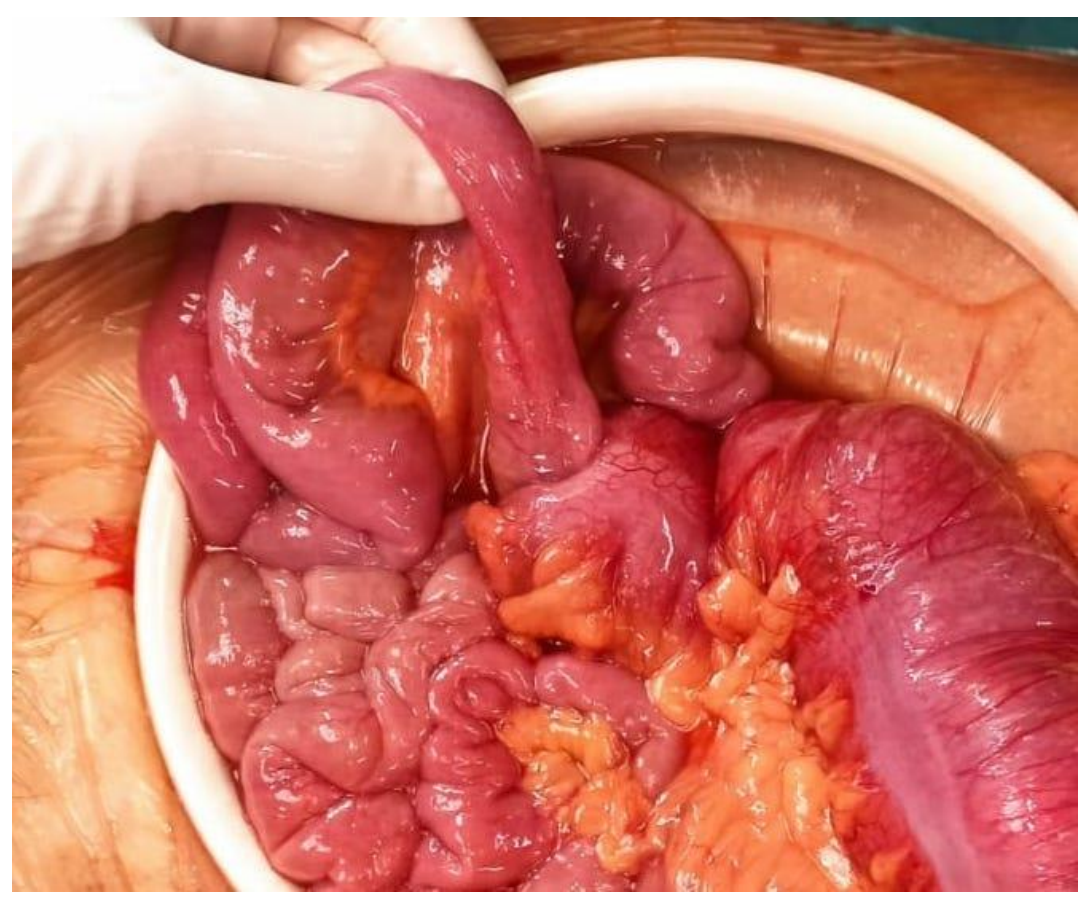

Imagen 4: Invaginación ileo-cólica.

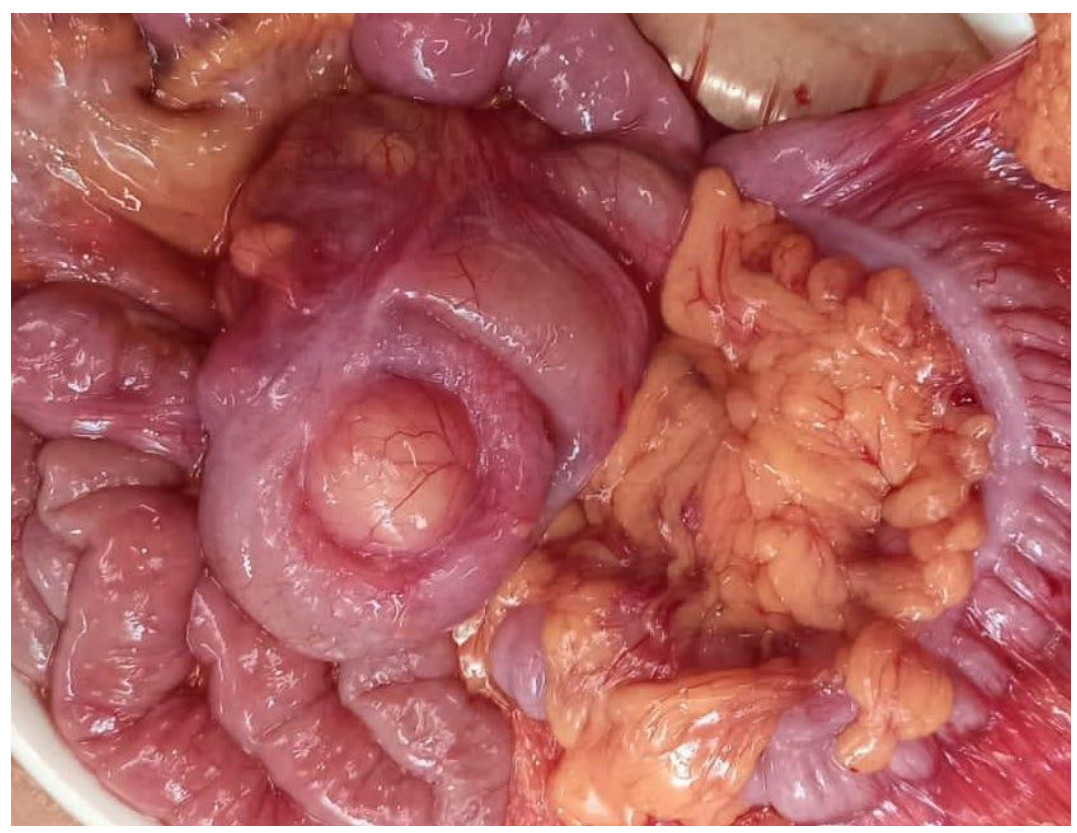

Imagen 5: Lesión causante de la invaginación, redondeada, elástica, en el grosor de la pared intestinal y sin afectación de la válvula ileocecal, con aspecto macroscópico de lipoma. 
La intususcepción representa menos del 5\% de los casos de obstrucción intestinal en el adulto ${ }^{2}$. Suele ser secundaria a lesiones intestinales $(65 \%)^{3}$, por lo tiene indicación de tratamiento quirúrgico.

Los lipomas son un tumor intestinal raro, mas frecuentes en ciego y colon ascendente, que afectan a mujeres entre los 50 y 60 años $^{4}$. Raramente son sintomáticos y su diagnostico es incidental. Los mayores de $2 \mathrm{~cm}$ pueden causar obstrucción intestinal. Aquellos mayores de $5 \mathrm{~cm}$ causan síntomas en el 75\% de los $\operatorname{casos}^{5}$. El diagnóstico es radiológico, por ecografía y $\mathrm{TC}$.

\section{BIBLIOGRAFÍA}

1. El-Sergany A, Darwish A, Mehta P, Mahmoud A. Community teaching hospital surgical experience with adult intussusception: Study of nine cases and literature review. Int J Surg Case Rep. 2015;12:26-30. doi:10.1016/j.ijscr.2015.03.032

2. Marsicovetere P, Ivatury SJ, White B, Holubar SD. Intestinal Intussusception: Etiology, Diagnosis, and Treatment. Clin Colon Rectal Surg. 2017;30(1):30-39. doi:10.1055/s-0036-1593429

3. Nagorney DM, Sarr MG, Mcllrath. Surgical management of intussusception in the adult. Ann. Surg. 1981; 193:230-236.

4. De Figueiredo LO, Garcia DPC, Alberti LR, et al. Colo-colonic intussusception due to large submucous lipoma: A case report. Int J Surg Case Rep. 2016;28:107-110. doi:10.1016/j.ijscr.2016.09.006

5. Ongom PA, Wabing H, Lukande R. A giant intraluminal lipoma presenting with intussusception in an adult: a case report. J. Med. Case Report 2012; 29(Oct 6):370. 